\title{
LECCIONES DE LA VIVIENDA PARA CONSTRUIR CIUDAD: MEGAFORMAS PARA LA REMODELACIÓN DEL CENTRO DE SANTIAGO DE CHILE
}

Megaforms For The Urban Renewal Of Santiago De Chile City Center. Housing Design And Its Lessons For New Urban Patterns In Latin American Cities

\author{
Ana Maria Rigotti \\ CONICET - CURDIUR Universidad Nacional de Rosario \\ amirigotti@gmail.com
}

\section{Resumen}

Las megaformas fueron un intento mayor, desde la Arquitectura, para decir algo significativo sobre la dimensión construida de la ciudad apoyándose en la densidad, la superposición de funciones, la verticalización del suelo urbano y la ampliación de las posibilidades de participación y cambio. Las tres propuestas argentinas en el concurso para la Remodelación de un área del Centro de Santiago de Chile (1972) permiten reconstruir los contornos de un debate sobre las megaformas que atravesó los países del Cono Sur. Recursos madurados en torno a la vivienda (planta libre, superposición de niveles, drástica autonomía de la envolvente respecto a la estructura, flexibilidad como indeterminación) fueron recuperados para proponer un tejido urbano alternativo al damero colonial que acompañara un camino pacífico hacia el socialismo.

\section{Palabras claves}

Megaestructuras, mat building, ciudad en el espacio

\begin{abstract}
Las megaformas fueron un intento mayor, desde la Arquitectura, para decir algo significativo sobre la dimensión construida de la ciudad apoyándose en la densidad, la superposición de funciones, la verticalización del suelo urbano y la ampliación de las posibilidades de participación y cambio. Las tres propuestas argentinas en el concurso para la Remodelación de un área del Centro de Santiago de Chile (1972) permiten reconstruir los contornos de un debate sobre las megaformas que atravesó los países del Cono Sur. Recursos madurados en torno a la vivienda (planta libre, superposición de niveles, drástica autonomía de la envolvente respecto a la estructura, flexibilidad como indeterminación) fueron recuperados para proponer un tejido urbano alternativo al damero colonial que acompañara un camino pacífico hacia el socialismo.
\end{abstract}




\section{Keywords}

Megaestructuras, mat building, ciudad en el espacio

Resulta conocido cómo las reconstrucciones en la posguerra europea y los nuevos sectores urbanos producto de las políticas de vivienda pública de los Estados de Bienestar, incluso en Latinoamérica, desencadenaron extendidos cuestionamientos a la redefinición analítica y segregativa de la ciudad. Las insuficiencias propias de una aproximación cartesiana al hecho urbano como camino a su replanteo sobre nuevas bases, a partir de la reformulación tipológica de las llamadas cuatro funciones, se asociaba al fracaso de una aproximación celular de la vivienda desvinculada de la calle corredor que, aunando circulación vehicular y peatonal, había sustentado la matriz pública de la ciudad histórica. Simplificando, las nuevas conformaciones surgidas del ensamble de vías clasificadas de transporte y del sabio juego de volúmenes edilicios exentos destinados al habitar y el trabajo, habían reducido el espacio común a un tapiz verde destinado a desplazamientos contemplativos peatonales y a un ocio asociado al cultivo del cuerpo con connotaciones extremadamente individualistas.

Aún dentro del área de influencia del CIAM -el VIII congreso en Hoddeston (1951); la Graduate School of Design de Harvard bajo la dirección de Josep Lluís Sert (1953/1969)- maduró un primer intento de recuperar espacios para la sociabilidad cotidiana y la vida cívica. Se las consideraba amenazadas por crecientes niveles de apatía adjudicados a la dispersión urbana y la congestión del tráfico que aislaban al hombre del hombre mediante barreras artificiales, y por la manipulación de la opinión pública a través de los medios de comunicación de masas. Se buscó la respuesta en una quinta función -el core urbano- como espacio catalizador del sentido de comunidad, apto para los encuentros programados y espontáneos que alentaran los intercambios y la discusión. Serían foco de concentración e irradiación de significados e identidad. Para idear estos nuevos espacios bajo el imperio del peatón se promovió una reinterpretación del ágora griega y las piazzas mediterráneas; incluso se fundamentó un nuevo saber -el Urban Design- que a través de la imaginación y las capacidades artísticas abordara la forma física de la ciudad articulando Arquitectura, Urbanismo y Paisajismo. Se buscaba superar la composición de masas y la organización por ejes beaux arts mediante lo que Sigfried Gideon denominó "imaginación espacial": la disposición de volúmenes edificados que eluden los límites y la simetría en espacios abiertos, alternativamente centrípetos y centrífugos, "[...] 
donde el hombre ocupa el lugar de los elementos naturales en el paisaje convencional y la geometría extiende su soberanía" (SERT, 1955, p.77) y de lo cual Brasilia es uno de los ejemplos más elocuentes.

Sin embargo, crecieron las demandas de una recuperación más rica de la sociabilidad espontánea y diversa a la que estos criterios compositivos y lingüísticos modernos parecían no dar respuesta. Apoyándose en la libertad de elección, el juego y la participación, esta sociabilidad se desplegaría en distintas escalas de asociación y en todo el entramado urbano para recuperar un sentido de comunidad desde lo cotidiano que se reconocía en la ciudad histórica, principalmente en los barrios populares. Sus modelos se buscaron en las agrupaciones de los pueblos mediterráneos y en la espacialidad árabe (RIGOTTI, 2013). Desde distintas fuentes y con una profusa diversidad de expresiones, estas búsquedas coagularon en una nueva apuesta desde la Arquitectura para proponer algo relevante respecto a la dimensión construida de la ciudad, en franco contraste con su radical desplazamiento por parte de la Planificación Urbana abroquelada tras las cifras y las variables económicas, demográficas y sociales. Nos referimos a las megaformas: edificios a escala ingenieril capaces de resolver la conflictividad del tráfico y una buscada densidad y mezcla de actividades mediante la verticalización del suelo urbano y la resolución tridimensional de las infraestructuras. Con algunas indagaciones rastreables hasta 1950, como el proyecto para la Ciudad Universitaria de Tucumán "allí donde la cuestión comenzó" (BANHAM, 1976, p.10), constituyó un fenómeno global y epocal de los años sesenta. En la saga de los passages parisinos, a través de interiores ampliados que remedaban in vitro el espacio abierto bajo un clima regulado (RIGOTTI, 2012b), exploraron la posibilidad de conjugar la estabilidad de lo construido y la variabilidad de las prácticas sociales reforzando vivencias de urbanidad mediante la articulación de sucedáneos de calles y plazas a diferentes niveles y la multiplicación de los encuentros y la percepción de los otros. Estas megaformas cuajaron en un conjunto múltiple de experiencias que hemos cartografiado como megaestructuras, con grandes esqueletos de sostén estables combinados con unidades espaciales discretas y sustituibles, y formas grupales definidas por el ensamble de componentes, entre las cuales también incluimos el mat building y algunas expresiones de la llamada arquitectura de sistemas (RIGOTTI, 2013). 


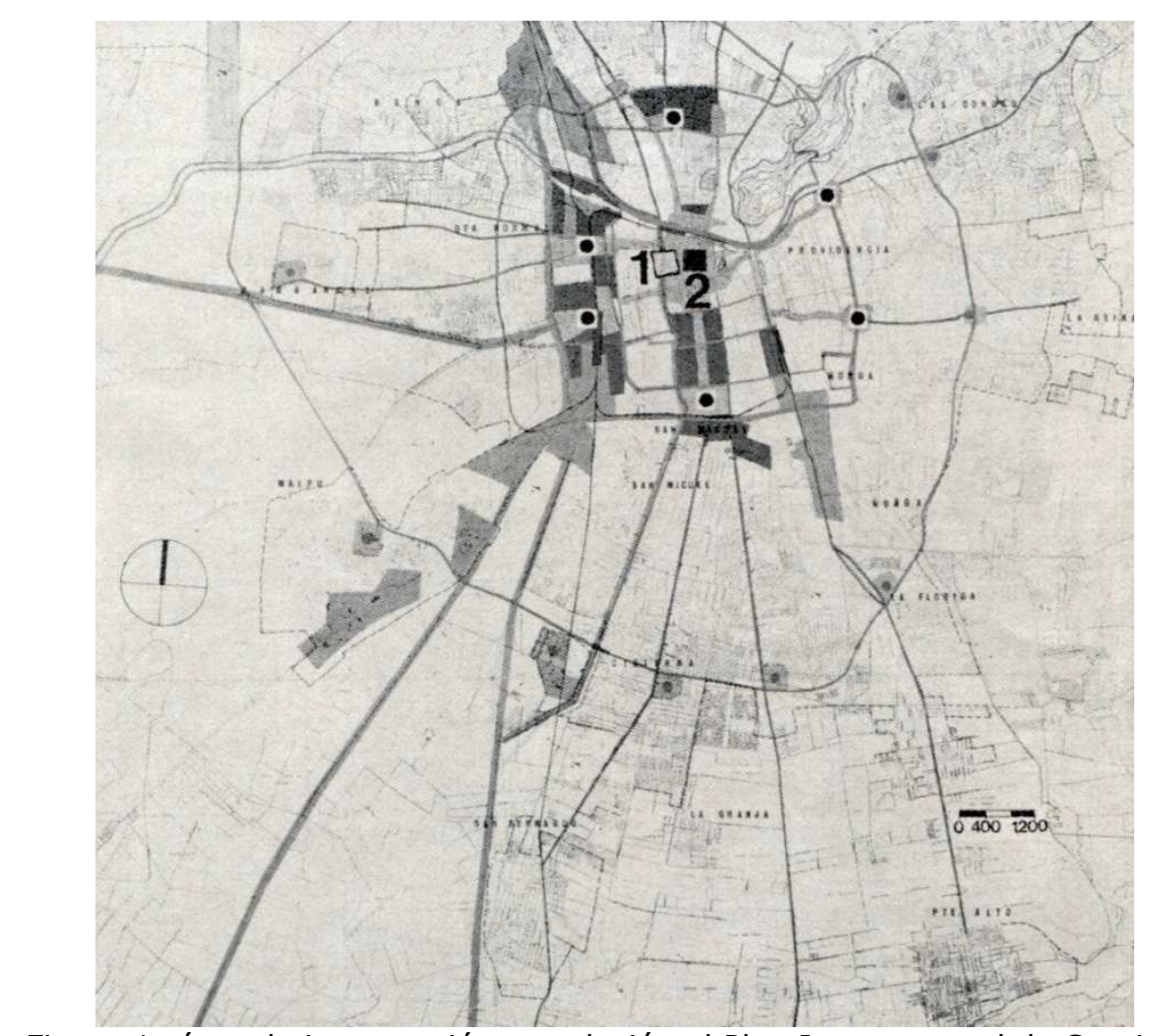

Figura 1: área de intervención en relación al Plan Intercomunal de Santiago

Fonte: Summa, n.87, marzo 1975, p. 25

En un clima de generalizado optimismo y confianza en las posibilidades de la técnica promovidos por el paradigma desarrollista, y a pesar de las crecientes reservas frente al costo social que suponían estas intervenciones contundentes, también el Cono Sur se vio seducido por las posibilidades de estos grandes edificios que prometían una urbanidad intensa y diversa al caos y la fragmentación de la ciudad real (RIGOTTI, 2012a). En este clima de ideas, el llamado a remodelar un sector del centro de Santiago de Chile fue percibido con beneplácito como una de las apuestas más radicales del gobierno de la Unión Popular. Se trataba de un concurso internacional de ideas organizado por la Corporación de Mejoramiento Urbano (CORMU) del gobierno socialista chileno, con el patrocinio de la UIA, en marzo de 1972. Suponía la continuidad de políticas de rehabilitación y densificación de áreas degradadas ya iniciadas por el gobierno anterior con el conjunto San Borja (1969) y continuado con la Remodelación de Tupac Amaru (1971). Por otra parte, su jurado estaba encabezado por la estrella del Team 10, Aldo van Eyck, acompañado por representantes latinoamericanos de claro compromiso con la vanguardia política y disciplinar: Antonio Quintana de Cuba, João B. Vilanova Artigas de Brasil, Marcos Winograd de Argentina Santiago Augurto de Perú, además de los chilenos H. Valdés, J. Wong, M. Bedrack y Miguel Lawner de Chile. (AREA DE REMODELACION..., 1973). 
El concurso fue reconocido como una oportunidad y para él calificaron 87 proyectos de 25 países, aunque sin la participación de personajes relevantes. Entre los aspectos que contribuían a su excepcionalidad podemos mencionar cinco. 1) La escala: 25 ha allende el centro histórico con la alternativa de oficiar como prototipo para otras áreas de renovación de tejido residencial degradado. 2) El programa: una ampliación del equipamiento metropolitano combinado con viviendas para 20.000 personas con su equipamiento comunitario en una ciudad capital latinoamericana en expansión. 3) El objetivo convergente con los principios del Urban Design: rectificar los procesos de extensión descontrolada del área urbana "[...]sobre la base de densificar las áreas vecinas al corazón de la ciudad, normalmente en estado de deterioro, que gozan de un alto nivel de urbanización y equipamiento" (ARQUITECTURA-CIUDAD..., 1975, p.24). 4) El desafío urbanístico implícito: proponer un tejido alternativo al damero colonial obsoleto por los nuevos sistemas de movilidad y la escala edilicia permitida por la técnica, resolviendo al mismo tiempo la integración de grandes infraestructuras y la recreación del ambiente de la calle corredor. 5) El contexto político: la presidencia de Salvador Allende desde la que se hacía un llamado a la solidaridad de la comunidad internacional de arquitectos para sentar las base de una futura sociedad socialista en un país en vías de desarrollo proponiendo "[...] rectificar los procesos que habían llevado a una segregación ecológica de los diferentes estratos sociales [...]" considerando "[...] la integración social y de actividades, criterio que se plantea como absolutamente complementario de los conceptos de planificación física." (ARQUITECTURA-CIUDAD..., 1975, p.24).

En este trabajo nos detenemos sólo en las tres propuestas argentinas. Lo justifica su relevancia (primer premio, tercera mención y uno sin premiar pero que mereció una publicación) pero también el hecho de que por despegarse de las particularidades locales son más esquemáticas y permiten desplegar los contornos de un debate teórico intenso que atravesaba los países sudamericanos. El primer premio se propone reconocer distintos niveles de asociación mediante una estratificación vertical del suelo urbano que alcanza a las mismas viviendas. La tercera mención propone sustituir el damero por una ciudad en el espacio resuelta por una trama estructural, infraestructural y circulatoria tridimensional que elabora plásticamente la idea de edificio tapiz. El último es un ensayo radical sobre la indeterminación y la participación mediante un groundscraper entendido como estructura posibilitante.

Cada una de las propuestas apostó a diferentes formas de conjugar la Arquitectura con el Urbanismo, la vivienda con la ciudad. Lo primero, reinterpretando 
desde la Arquitectura elementos urbanos: calles, puentes, escaleras públicas, recovas, señalética; incluso fachadas y cuerpos edilicios. Lo segundo, incorporando en estos fragmentos de ciudad la flexibilidad y la indeterminación desde recursos ensayados en la vivienda como campo privilegiado de experimentación espacial y constructiva del ciclo moderno: planta libre, extensión horizontal, raumplan, ruptura de la caja, interacción interior/exterior, diferenciación entre estructuras y envolventes, previsión de lógicas de crecimiento, concepto de terrain artificial. Incluso, el modo en que enfrentan la definición de los espacios de la vivienda nos dan claves para entender los alcances de la resolución del tejido urbano alternativo definido dentro de los parámetros de las megaestructuras y las formas grupales.

\section{La estratificación vertical del suelo urbano}

El proyecto ganador correspondió a una propuesta que, si bien no se considero "un aporte renovador y estimulante" (AREA DE REMODELACIÓN..., 1973, p.24), satisfizo a un jurado reacio a considerar ejercicios de futurología o imágenes radicales que implicaran una transición abrupta con el contexto físico y cultural chileno. Se lo apreció por su resolución formalmente clara que favorecía su articulación con la ciudad preexistente -entre otras cosas al sostener "[...] la promesa esperanzada de la cuadrícula como gesto democrático." (SESSA, 2011, p.14)- aunque expresando una integración social superadora de las fórmulas empleadas hasta el momento en el país. Se destacó su factibilidad con la tecnología disponible, la razonabilidad de su costo sin incorporar áreas techadas para funciones de segundo orden propio de las megaestructuras y el ordenado sistema de movimiento y equipamientos en niveles múltiples. El relativo esquematismo de la propuesta, con una resolución autónoma de unidades vecinales, la hacía particularmente viable para su reproducción en otras áreas degradadas, cumpliendo con el objetivo de un desarrollo gradual en etapas por distintos equipos de arquitectos y tomando en consideración las lecciones de los ensayos previos. Se presentó como una resolución volumétrica atractiva y grata, especialmente apreciable en las maquetas $y$ en perspectivas que sabiamente integraban la figura humana en acción y el mobiliario urbano. La continuidad con un centro histórico totalmente peatonalizado se lograba a través de una red de calles aéreas y fajas de penetración de lo metropolitano sin focos de intensidad de mayor escala. Esto último fue observado, junto con la pobreza de matices en la disposición espacial y volumétrica, especialmente de las torres de altura uniforme en excesivo contraste con el resto de las construcciones. 


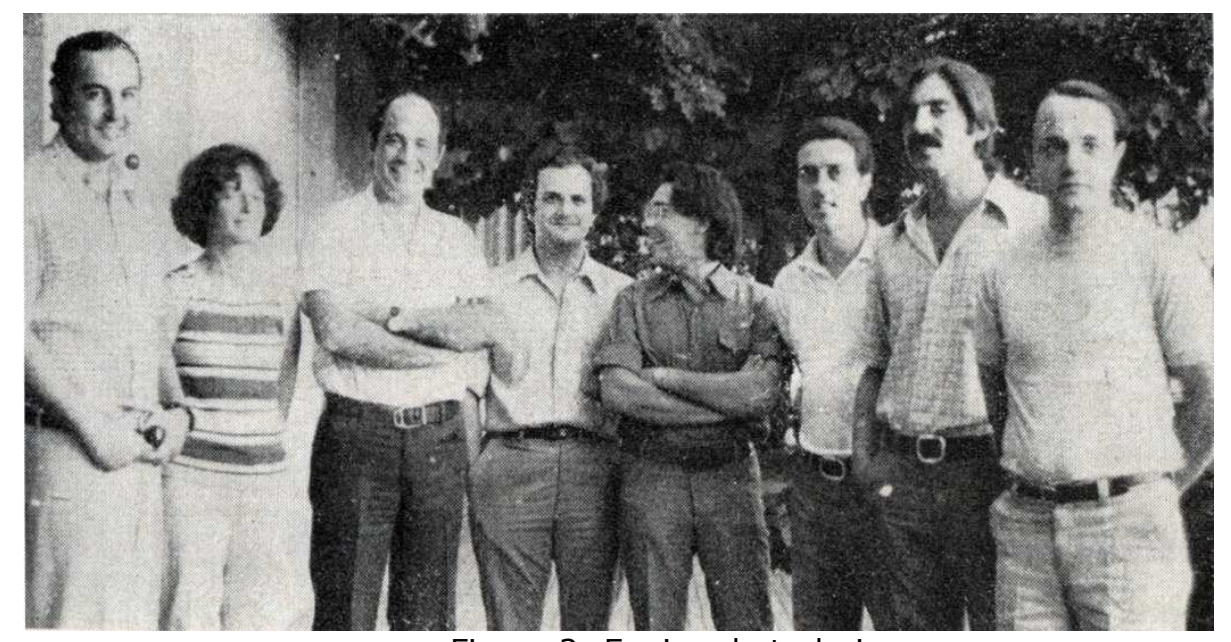

Figura 2: Equipo de trabajo

Fonte: Summa, n.87, marzo 1975, p. 24

La iniciativa planteaba superar la concepción de edificios aislados por una "arquitectura ciudad" cuya única variación respecto a las composiciones volumétricas modernas era su cosido por pasajes peatonales a dos niveles. Pertenecía a un equipo de jóvenes arquitectos recibidos en la Universidad de La Plata conformado por Enrique Bares, Santiago Bó, Tomás García, Roberto Germani y Emilio Sessa. Su mentor había sido Marcos Winograd, casualmente miembro del jurado, con posgrados en el Centre de Recherche d'Urbanisme y la École Pratique de Hautes Etudes de Paris y una participación directa en la experiencia de Bologna con Giuseppe Campos Venuti. En relación con su maestro, el equipo asumía una posición humanista frente a la cuestión urbana y de la vivienda social, con lecturas de Henri Lefebvre, cuyo Derecho a la ciudad había sido publicado en castellano tres años antes. Conocían, por publicaciones, la obra de Candilis, Josic y Woods y, como veremos, de J. H. van der Broek y J. B. Bakema. Incluso algunos habían incursionado en propuestas asimilables a las megaformas en los concursos para el Centro Cívico de Berisso y la terminal de ómnibus de Azul. 


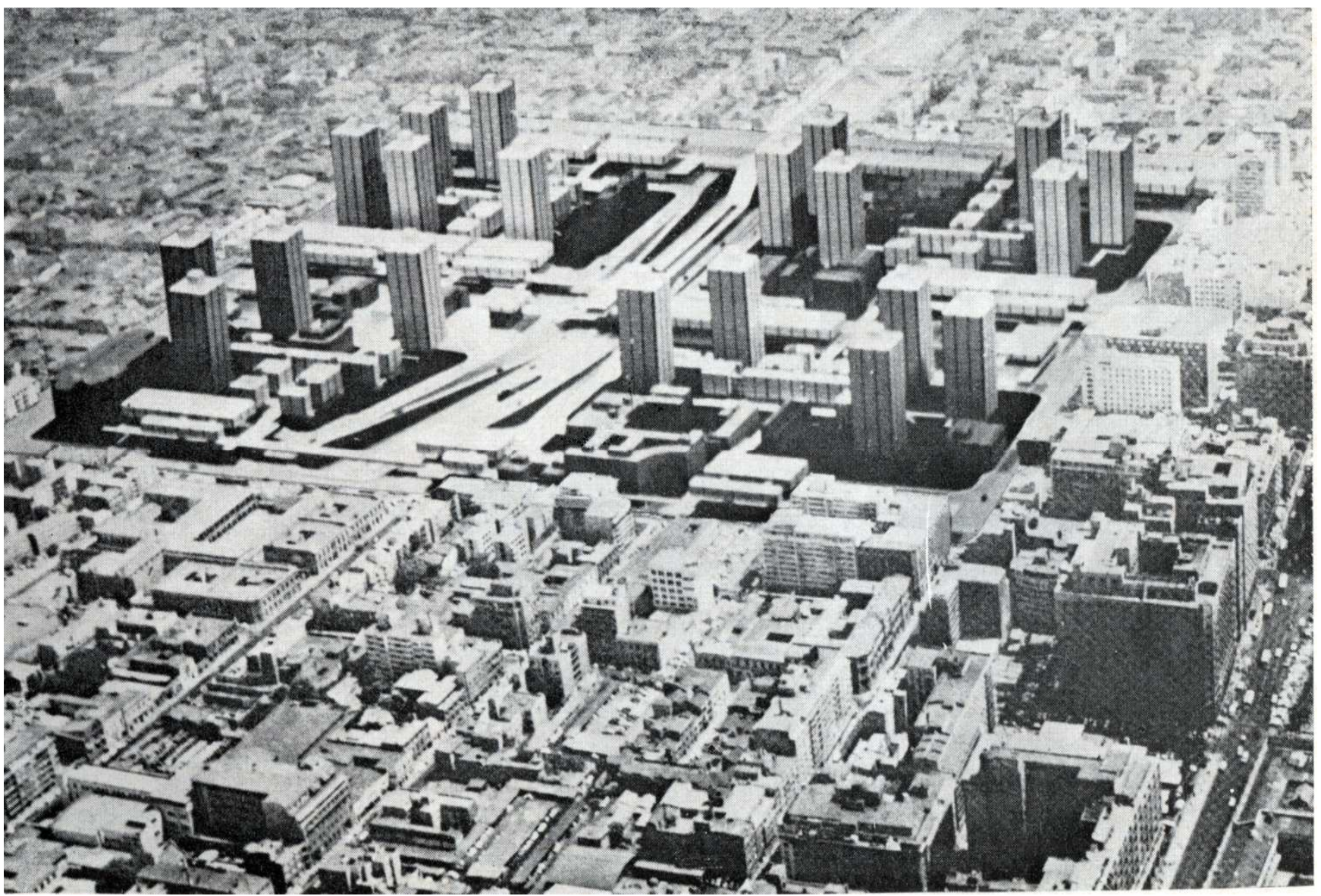

Figura 3: Fotomontaje

Fonte: Summa, n.87, marzo 1975, p. 23

El diagnóstico del jurado se hace evidente en las propuestas para las viviendas. El proyecto asume con prolijidad las demandas de las bases: mitad de la superficie construible con una densidad bruta de 800/900 hab /ha. A pesar de que las viviendas agrupadas en torres de veintiún pisos y bloques de cuatro se sostienen con una estructura independiente de tabiques porticados, las unidades están resueltas según las pautas usuales de la planta compacta moderna, fijando con precisión la distribución en locales convencionales articulados por un corredor neutro y cuyos tres tipos se diferencian sólo por el número de dormitorios. 


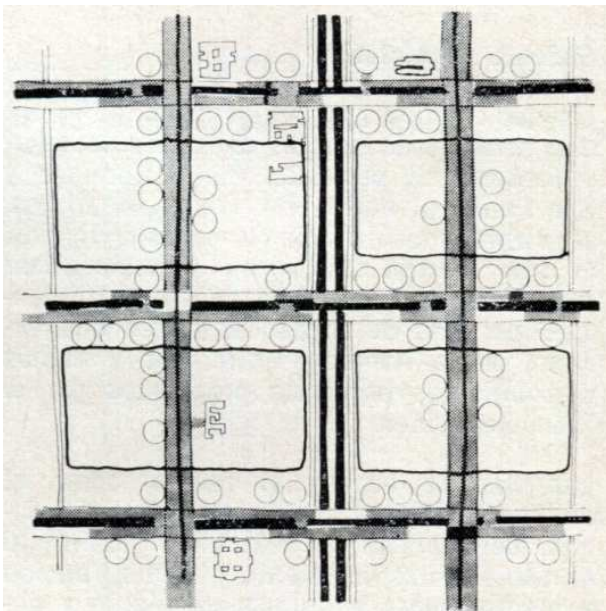

Figura 4: esquema circulatorio y de los Módulos Urbanos Sectoriales

Fonte: Summa, n.87, marzo 1975, p. 32

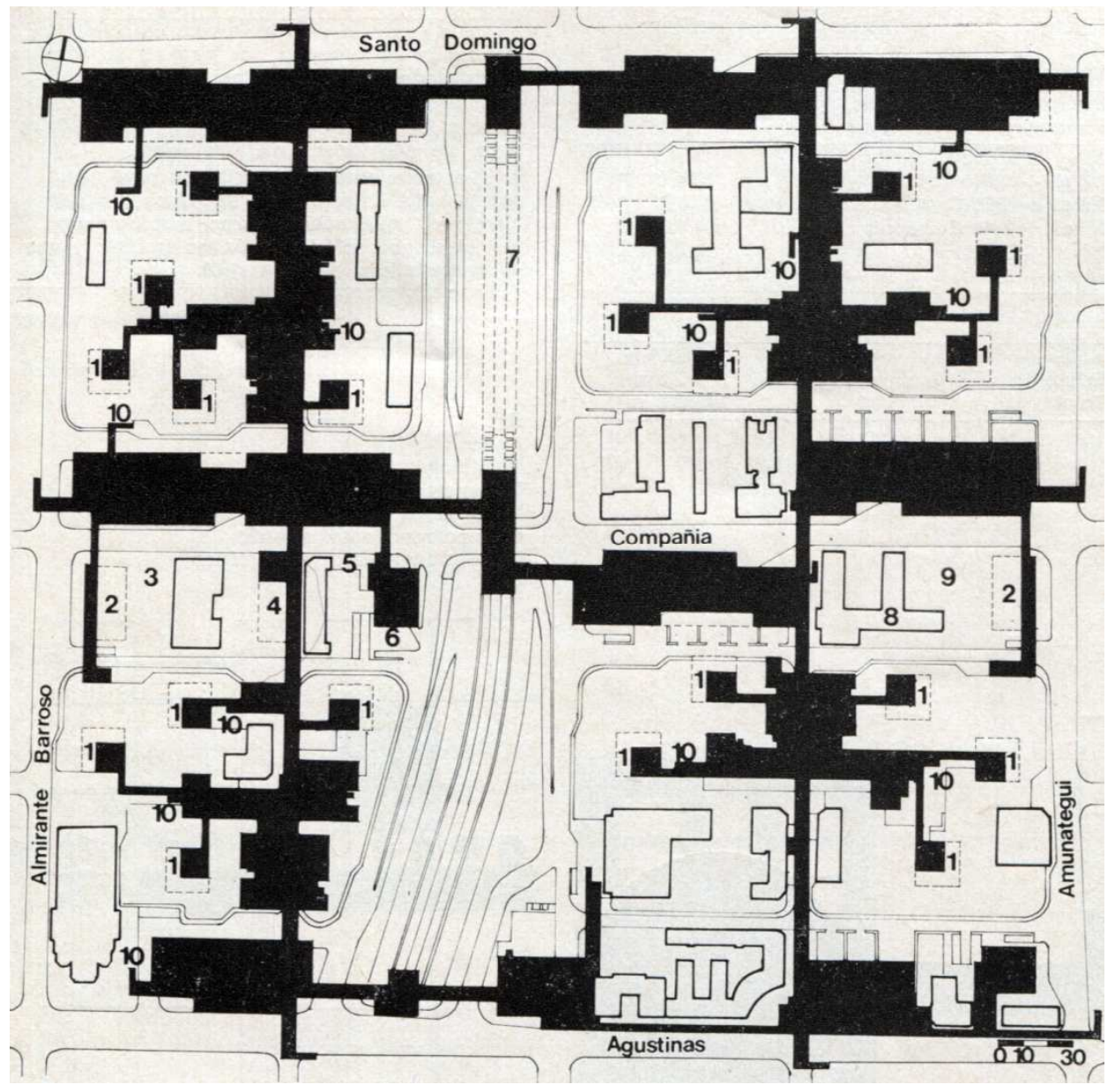

Figura 5: planta de nivel $+3.00+5.60$ mostrando recorridos peatonales Fonte: Summa, n.87, marzo 1975, p. 23

Esta compartimentación funcional se traslada al planteo del conjunto. Se diferencian con claridad las fajas de servicios metropolitanos sobre tres líneas de 
penetración vehicular que repiten el esquema de la ciudad de Berna difundido como ejemplo en El corazón de la ciudad (GIDEON, 1955, p.17). Junto con la avenida NorteSur que atraviesa el área, sirven para discriminar cuatro Módulos Urbanos Sectoriales de alta densidad sobre la integración de cuatro manzanas preexistentes. Focos del desarrollo comunitario a un nivel intermedio entre el individuo y la ciudad, permitirían la inervación de lo cívico administrativo con la vida cotidiana y el contacto del habitar popular con las ventajas del centro. Se trata de unidades vecinales, delimitadas y protegidas del ruido del tráfico por la pantalla virtual de las torres, que se vuelven hacia un interior salpicado de equipamientos comerciales, educativos y de salud sobre un sustrato verde para difusas actividades recreativas

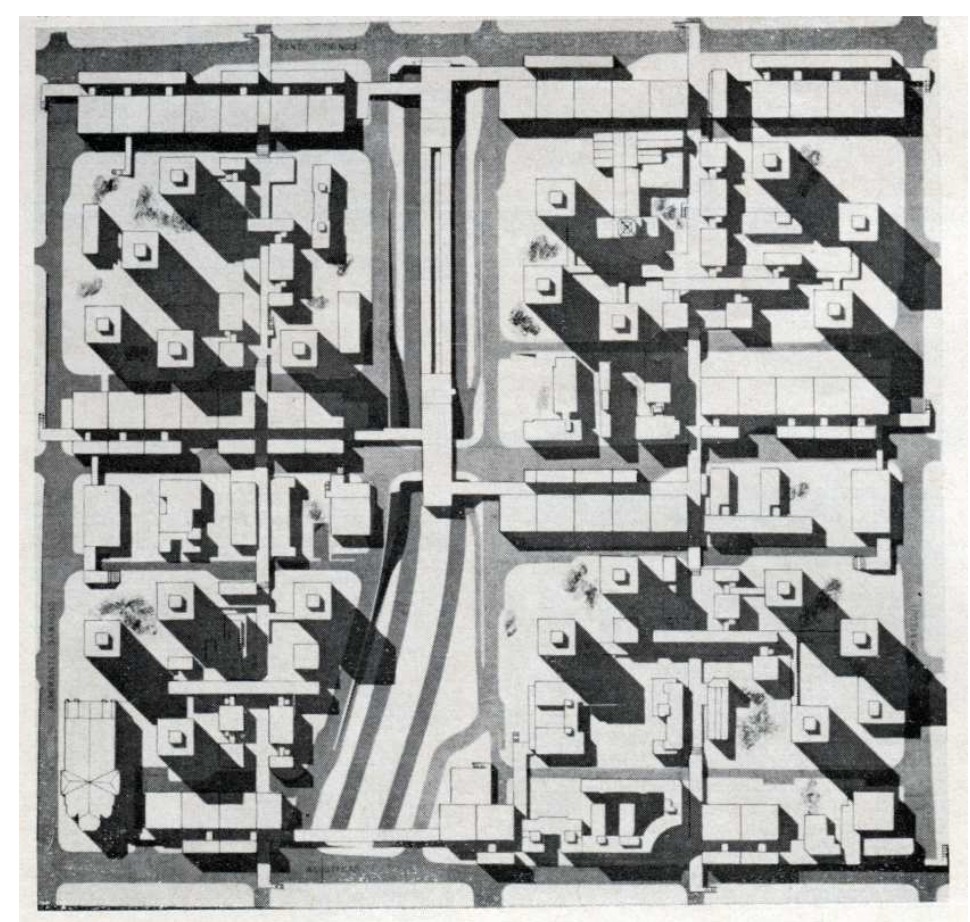

Figura 6: planta de techos

Fonte: Summa, n.87, marzo 1975, p. 32

Dos son las innovaciones propuestas que se complementan. Por una parte, el entramado elevado de pasajes peatonales que en un primer nivel $(+3.00)$ cosen los accesos a las viviendas y los servicios vecinales y en un segundo nivel $(+5,60)$ atraviesan y diferencian en profundidad las barras para servicios metropolitanos. Por la otra, en estas barras se explotan las posibilidades de la planta libre con superficies continuas punteadas por un modulado estructural de $7,5 \mathrm{~m}$ de lado que se suponen suficientes para responder a las diferentes demandas programáticas que quedan en suspenso. La franca diferenciación de lo peatonal respecto a la circulación vehicular y los estacionamientos se resuelve por un hojaldrado del suelo urbano que sigue la impronta de la reconstrucción del área de Lijnbaan en Roterdam de van der Broek y 
Bakema (1948/1953). A pesar de su esquematismo, supone un avance respecto a la mera incorporación de calles elevadas a conjuntos de tiras (los proyectos PEVE de STAFF) o torres (el conjunto Rioja de MSGSSV). Esto lo entiende el jurado que, sin embargo, objeta la falta de relación arquitectónica y espacial entre los distintos niveles de la trama peatonal y la carencia de ámbitos "[...] que provoquen el contacto y la reunión de los habitantes, produciendo una apropiada asociación comunal." (AREA DE REMODELACIÓN..., 1973, p.24).

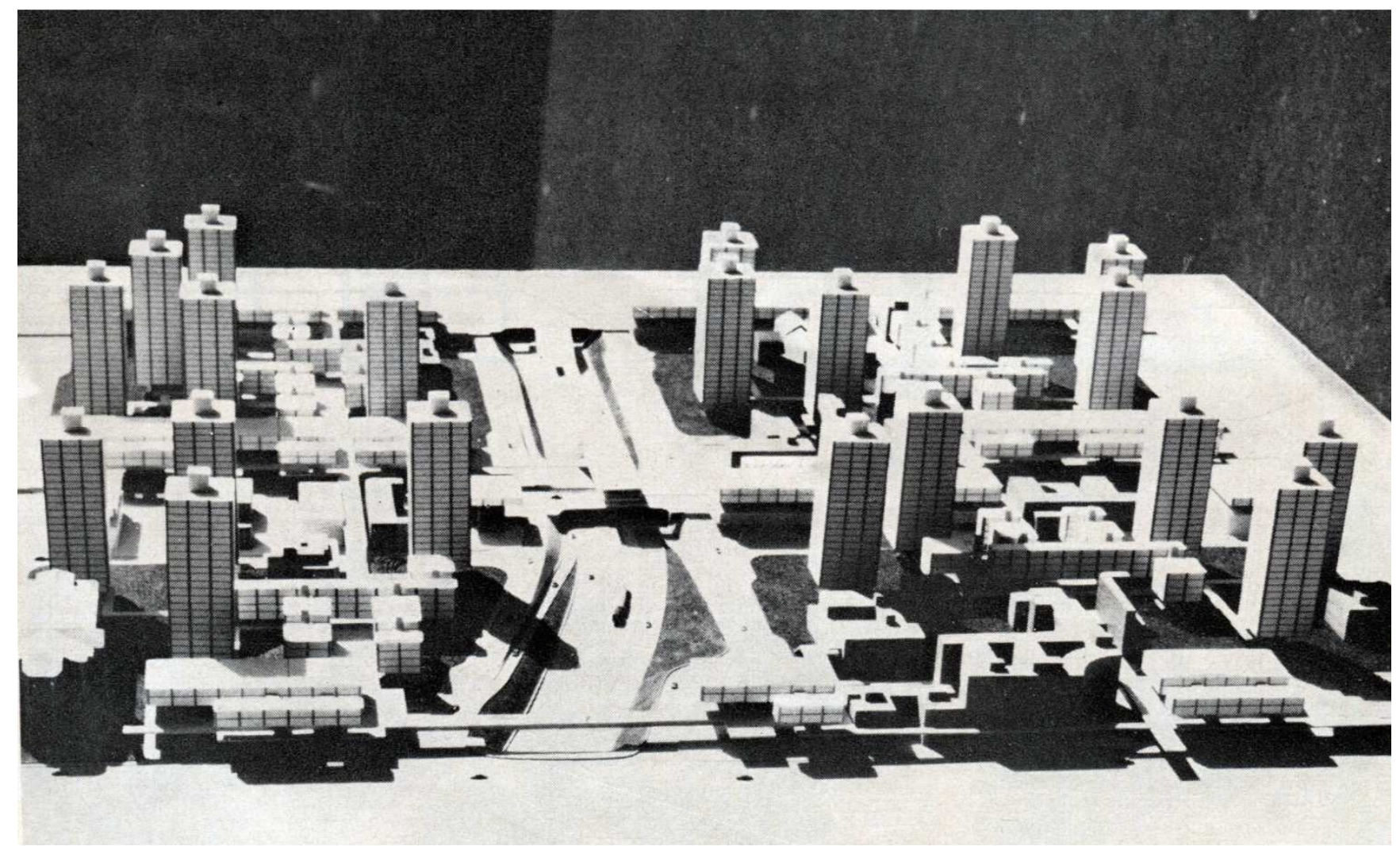

Figura 7: perspectivas mostrando volumetrías y enlace sobre la avenida Norte-Sur Fonte: Summa, n.87, marzo 1975, p. 34

A pesar de la pretendida conformación urbano/arquitectónica unitaria, el proyecto no dejaba de ser una composición de volúmenes en el espacio, con una silueta recortada que daba aspecto dinámico al conjunto atenuando la homogeneidad propia de la masividad y la repetición. La relativa pobreza de ámbitos urbanos de diferente jerarquía es lo que los autores procuraron revertir en la oportunidad que se les presentó, como ganadores del concurso, para desarrollar el anteproyecto de cuatro manzanas en el sector de la Iglesia Santa Ana y que, luego de un año de trabajo in situ, fue descontinuado dos semanas después del golpe de Estado. 
Nuevamente la resolución de las viviendas ofrece claves para apreciar los avances en la propuesta urbana. Las torres -"edificios ciudad"- fueron reconfiguradas como volúmenes porosos que remitían al edificio para el Hansaviertel de van der Broek y Bakema (1967). Reducidas en número y planteadas como un continuo articulado respecto a las viviendas en tira, se componían de dos volúmenes interconectados por puentes cada cinco niveles para recuperar una impronta de planta cuadrada, conveniente para responder a las solicitaciones sísmicas.

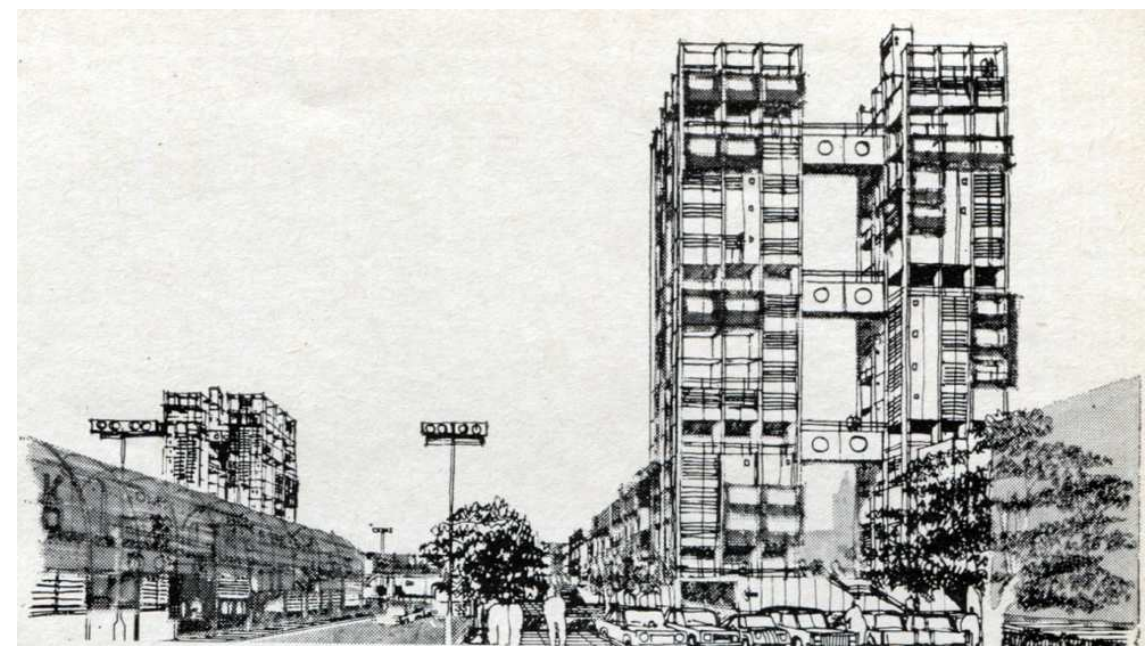

Figura 8: anteproyecto Santa Ana. Perspectiva mostrando la reconfiguración de las torres y los enlaces entre edificios

Fonte: Summa, n.87, marzo 1975, p. 44

Estos niveles intermedios buscaban recuperar y ampliar, en vertical, el rol asociativo de los pasajes peatonales. Concurrentes con la parada de los ascensores y específicamente destinados a salones de usos múltiples y solarios, el primero de los puentes se continuaba con la cubierta de las tiras de vivienda ahora trabajadas como terrazas jardín, integrándose en un sistema de espacios comunitarios que se extendían con tramos pergolados sobre nuevos elementos lineales para oficinas o talleres dentro de las unidades vecinales. Este desarrollo se perfeccionaba reduciendo el desnivel con las calles aéreas metropolitanas que, gracias a la topografía natural, permitía una continuidad más franca con el centro histórico. También se hacía un esfuerzo para complejizar los ejes metropolitanos, fragmentándolos, alternando las diferencias de profundidad a ambos lados de la calle peatonal elevada y agregando la posibilidad de edificios puntuales de forma indeterminada para programas "atípicos". El edificio de la iglesia a preservar es el que permite la ocasión de desarrollar una plaza. 
Dentro de los límites de una solución que insiste en la articulación de volúmenes de geometrías puras funcionalmente caracterizados, es destacable el esfuerzo para ampliar una variedad formal que acogiera y representara la diversidad de actividades que tejen la vida urbana. Lo mismo se hace con las viviendas, siempre sectorizadas, dentro de las cuales se incorporan algunas variaciones en las plantas y unidades de cuatro dormitorios, ampliando los espacios semicubiertos que, ahora, se denominan terrazas.

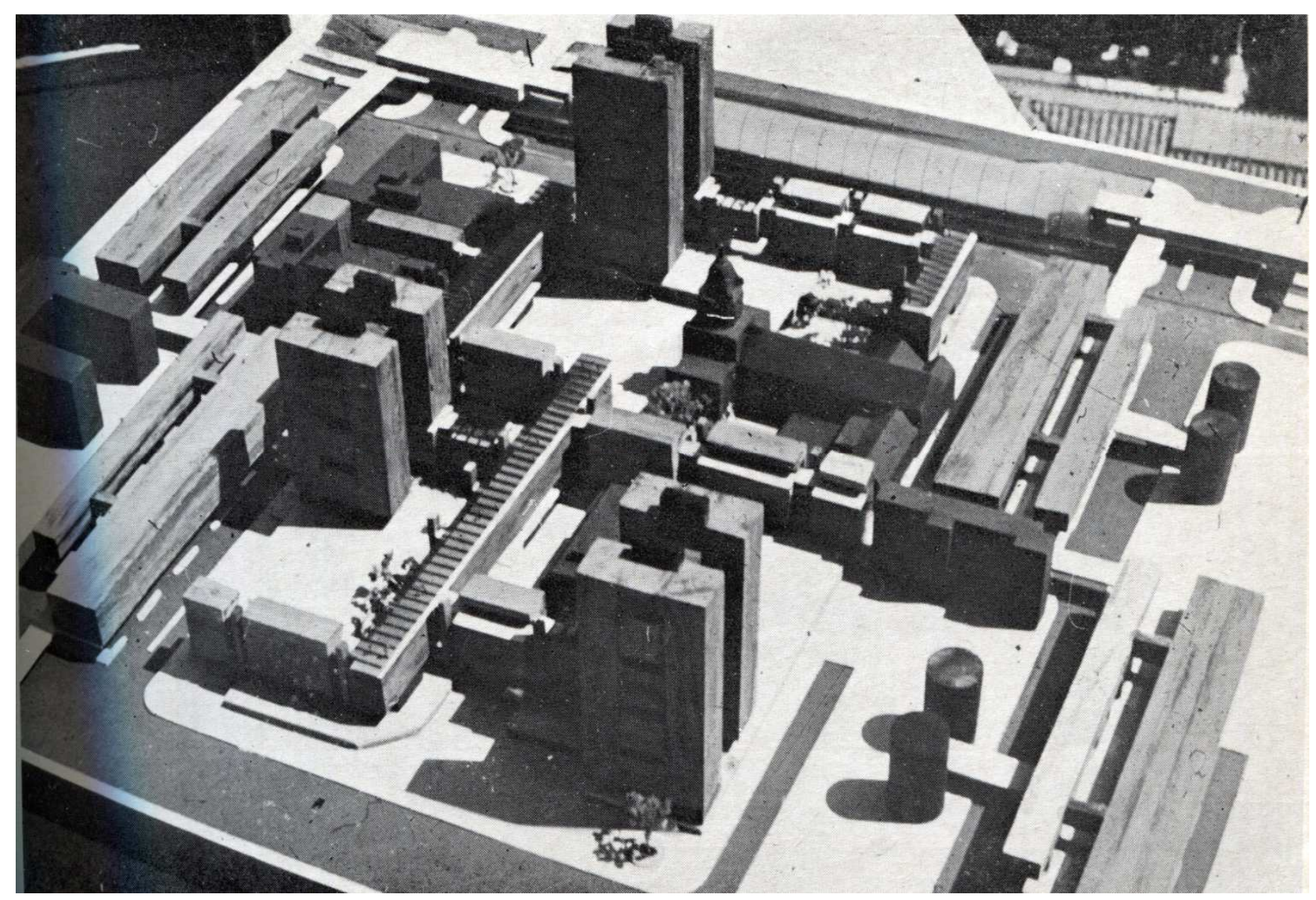

Figura 9: Anteproyecto sector Santa Ana, maqueta.

Fonte: Summa, n.87, marzo 1975, p. 23

\section{El tapiz como matriz de una ciudad en el espacio}

La noción de edificio tapiz o mat building fue definida retrospectivamente por Alison Smithson (1974, p. 313, traducción propia) como "[...] epitome del colectivo anónimo; donde las funciones enriquecen el tejido y el individuo gana nuevas habilidades de acción a través de un orden nuevo y entremezclado, basado en la interconexión, en el tejido apretado de patrones de asociación y en la posibilidad de crecimiento, disminución y cambio." Supo reunir un conjunto de indagaciones, en su 
mayoría de miembros del Team 10, que buscaron reinterpretar la espacialidad árabe arracimada, antimonumental, organizado por células multipropósito espontáneamente intercambiables bajo cubiertas livianas y con varios puntos de parada y cambios de dirección- en edificios que estimularan con contundencia la complejidad, la interacción, la participación y el cambio. Con antecedentes lejanos en la ciudad subterránea de Honan o la mezquita de Córdoba, sus expresiones emblemáticas se extienden desde Berlin Hauptstadt de los Smithson (1957/8) y el orfanato en Amsterdam de van Eyck (1957/60), hasta las propuestas para Frankfurt Römerberg y la Frei Universität de Berlin en Dahlem (1963) del equipo de Candilis, Josic y Woods, pasando por el centro comunitario en Ewing de Louis Kahn (1954), la Agricultural City de Kisho Kurokawa (1960) y aún el Hospital de Venecia de Le Corbusier y Guillermo Juillan (1962). Incluso hubo expresiones locales en la escuela para Acindar en Rosario, Argentina, de Harpa (1962) y la obra de Bresciani, Valdes, Castillo y Huidobro en Chile. Agregando y ensamblando elementos estructurales similares o entretejiendo entidades programáticas y espaciales variadas sobre una urdimbre de senderos peatonales, exploraron la alta densidad sobre una trama donde la porosidad de los patios era crucial como dispositivo climático y de interacción social, y lo permanente se reducía a un principio organizativo, casi infraestructural. Por su parte, el urbanismo espacial libertario de Yona Friedman (1958) proponía la superposición de la masa, la conflictividad y el desorden de la ciudad real (desplazando entonces decisiones sobre su sustitución, reforma o preservación) por una mega infraestructura tridimensional reticulada y liviana, en algunos casos a varios niveles, que ampliaría exponencialmente la participación de los usuarios en el diseño y la localización de su hábitat por medios interactivos. Elevada sobre pilotis contenedores de las circulaciones y servicios verticales, esta trama aérea de puentes, calles y plataformas sería receptiva a la disposición en sus intersticios de unidades espaciales discreta de fácil alteración y sustitución, marcando el camino para enfrentar las nuevas demandas de movilidad y concentración.

Ambas líneas de indagación confluyen en la propuesta acreedora de la tercera mención del Concurso de Ideas para Santiago. Fue presentada por la unión transitoria de dos exitosos estudios formados por jóvenes porteños: MSGSSV (Flora Monteola, Javier Sánchez Gómez, Josefina Santos, Justo Solsona y Rafael Viñoly) y STAFF ( Jorge Goldemberg, Ángela T. Bielus y Olga Wanstein-Krasuk). El primero aún se caracteriza por la calidad formal de una obra desprejuiciada, capaz de reinventarse a sí misma en su capacidad de seguir el pulso de lo nuevo en torno a ideas rectoras que se reformulan para cada encargo. Venían ensayando gestos totalizantes desde la URBANA, V.6, no 8, jun.2014 - Dossiê: Cidade e Habitação na América Latina - CIEC/UNICAMP 
presentación para la Biblioteca Nacional (1962) que, para la embajada argentina en Brasilia (1970) y los concursos para hospitales públicos (1971), asumen la indagación de órdenes megaestructurales suspendidos de edificios tapiz. El segundo equipo, bajo el liderazgo de Goldemberg con una intensa formación y experiencia en sociología y estudios urbanos como práctica interdisciplinaria, venía de ganar por concurso una serie de conjuntos de vivienda pública bajo la operatoria PEVE orientados a la relocalización de villas de emergencia. En ellos reformulaban la calle con pasarelas suspendidas y núcleos verticales articuladores de las actividades y ámbitos privilegiados de socialización. El estudio se destacaba por cierta preocupación teórica y un explícito compromiso ideológico que, despreciando la arquitectura objetual, entendía la práctica profesional como una contribución a los conflictos derivados de la desigualdad social. El contorno de este universo de referencias da cuenta de la compartida voluntad de los dos equipos de insertarse y terciar en los debates contemporáneos sobre grandes estructuras capaces de enfrentar la complejidad metropolitana y una concepción fuerte de flexibilidad en conjuntos que pudieran expandirse sin afectar una contundente imagen de unidad. Su confluencia dio como resultado una asimilación de lo revolucionario en el campo político y social con lo revolucionario en las formas.

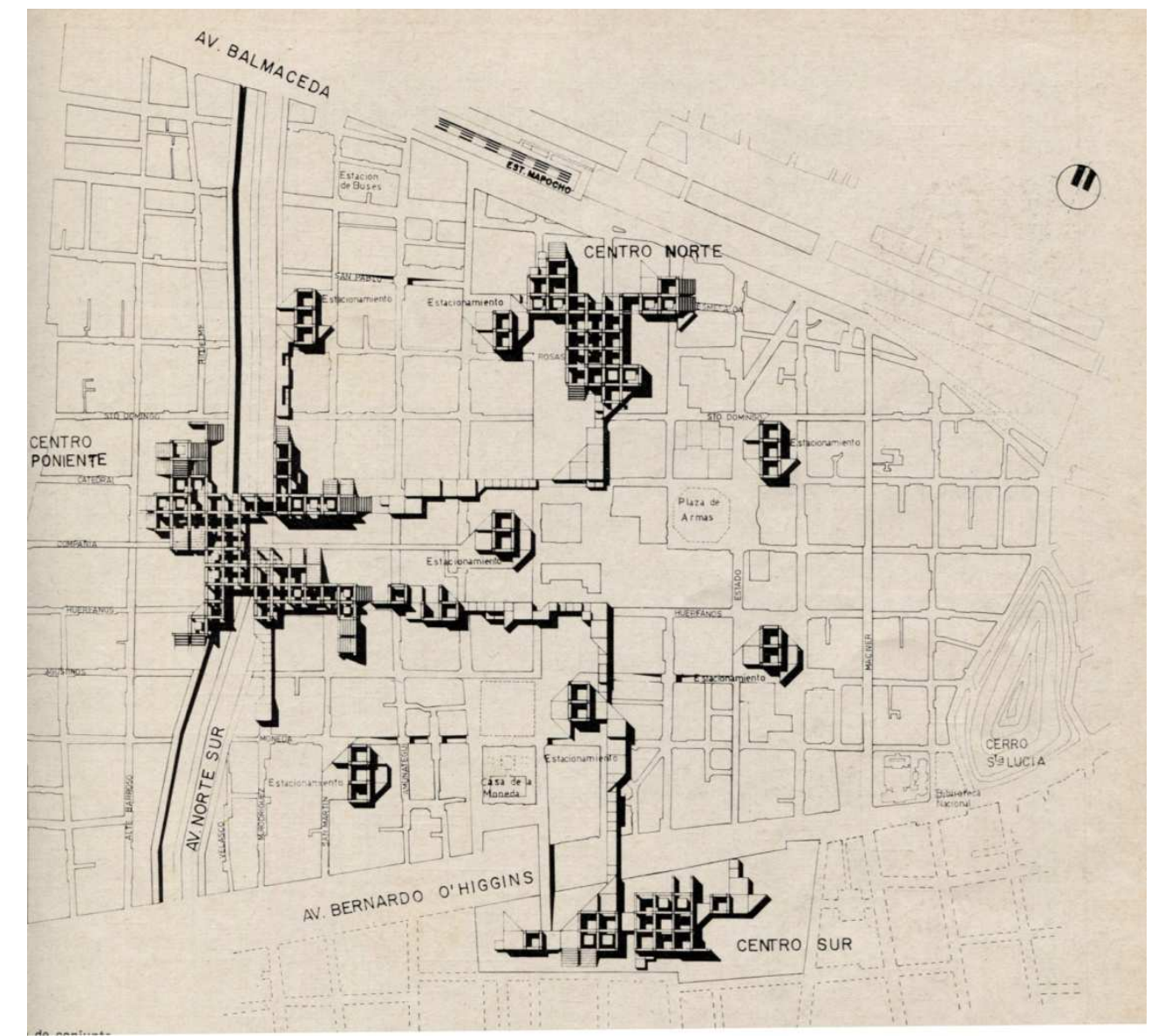


Figura 10: planta general con pólipos uniendo los centros planteados

Fonte: Summa, n. 64/63, julio 1973, p. 129

Las consideraciones del jurado dieron cuenta de las netas diferencias de este proyecto respecto a la apuesta ganadora. Lo valoraron como "una audaz e interesante idea" (AREA DE REMODELACIÓN..., 1973, p.30) para tratar integralmente los problemas urbanos, resolviendo en un mismo sistema las cuestiones circulatorias y las funciones residenciales y de servicios, con variedad en los tipos edilicios y amenidad en los juegos volumétricos. Lo incluían dentro de los proyectos "absolutos" caracterizados por "elevar la puntería" en la propuesta urbana global, aunque "vacilantes" frente a las exigencias concretas del problema (WINOGRAD, 1972, p.19).

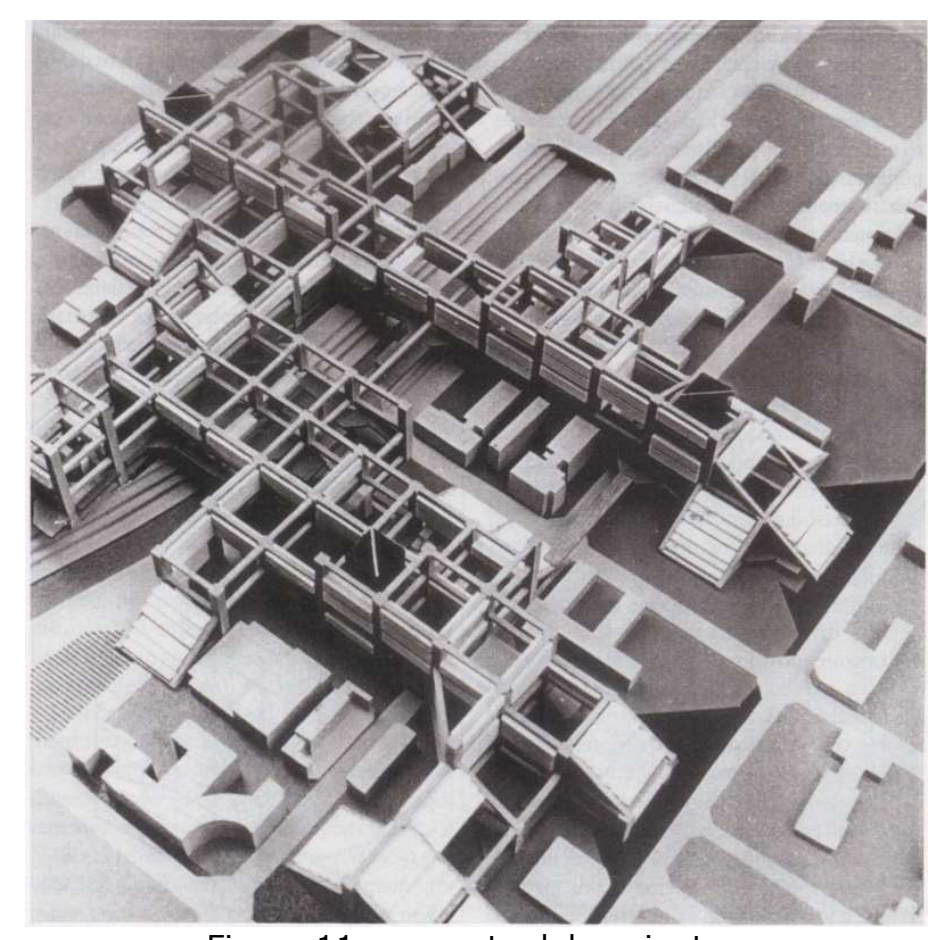

Figura 11: maqueta del conjunto

Fonte: Summa, n. 64/63, julio 1973, p. 129

Sin embargo, el jurado cuestiona una tecnología de alto costo y difícil ejecución aún en países de elevado poder económico y tecnológico, casi en el campo de la especulación futurológica. No sólo hubiera implicado la construcción inicial de una enorme estructura tridimensional que quedaría por un tiempo vacante, sino que suponía un cambio drástico difícil de conciliar con la trama existente de la ciudad. Todo esto es reconocido por el mismo Goldemberg (ESTUDIO STAF, 1973, p.128) que refiere a la experiencia como a "un PEVE sin tantas restricciones" en el que el desafío fue "[...] perforar la barrera de imposibilidades [...]" que amedrentaban y restringían URBANA, V.6, no 8, jun.2014 - Dossiê: Cidade e Habitação na América Latina - CIEC/UNICAMP 
las opciones a un arreglo limitado, supuestamente realista, de lo existente. Aún teniendo en cuenta las condiciones objetivas inmediatas, los autores se habían animado a proponer "[...] un estilo sudamericano creativo, potente y a la vez realista $[\ldots . .]^{\prime \prime}$ fundado en un reordenamiento vertical de la ciudad a través de una urdimbre de grandes grillas de comunicación y servicios cada seis niveles, supuestamente adaptable a las condiciones de la estructura tecnológica y social chilena.

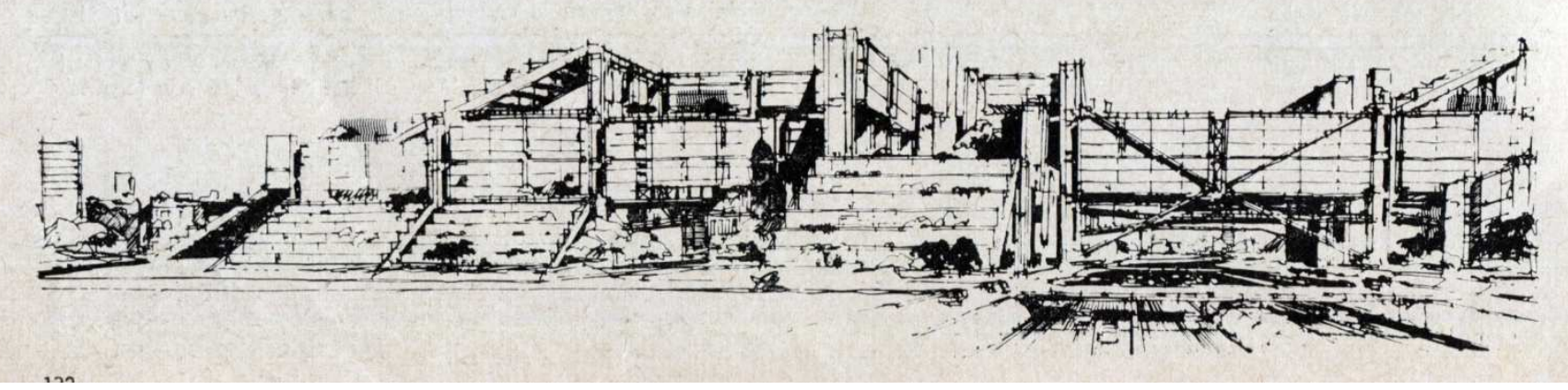

Figura 12: perspectivas mostrando las placas aterrazadas de vivienda

Fonte: Summa, n. 64/63, julio 1973, p. 132

En este proyecto, las viviendas son un componente sustancial, aunque complementario, respecto a la propuesta general. Conforman placas escalonadas de $30 \mathrm{~m}$ de largo que se extienden desde el suelo hasta el segundo nivel del entramado aéreo de calles y exploran la posibilidad de expansiones en terrazas, aún para unidades económicas de restringidas dimensiones. Pueden entenderse en relación a las Terrassenhäuser indagadas precursoramente por Walter Gropius en un esquema de 1928 (BANHAM, 1974, p.49) y explotadas con sistematicidad por Kenzo Tange para los desarrollos en el puerto de Boston (1959) y la bahía de Tokio (1960) y por Paul Rudolph en el Lower Manhattan Expressway (1970). Los autores ya habían ensayado estos perfiles diagonales de terrazas abiertas en la escuela de educación técnica J. F. Kennedy en Lanús (1964) y, en una expresión más extrema, en el anteproyecto de viviendas en La Pastora, Uruguay (1971). Más allá de su agrupamiento, un lugar destacable merece la propuesta de su organización interna. Bajo el concepto de "transformabilidad" inicial (WAISMAN, 1973, p.26), como alternativa a la flexibilidad en el tiempo por obsolescencia o sustitución propia de las economías desarrolladas e hipertecnificadas, en lugar de unidades de habitación convencionalmente distribuidas proponen plataformas que recuerdan el concepto de soporte (HABRAKEN, 1972). Se trata de superficies liberadas y convenientemente equipadas, puestas en disponibilidad para su futura organización interna y 
cerramiento por parte de sus habitantes. Esta versión del terrain artificial corbusierano, radicalizado por la noción de arquitectura móvil de Friedman, procuraba también reducir el rol paternalista asumido por el arquitecto moderno como reformador de los modos de vida.

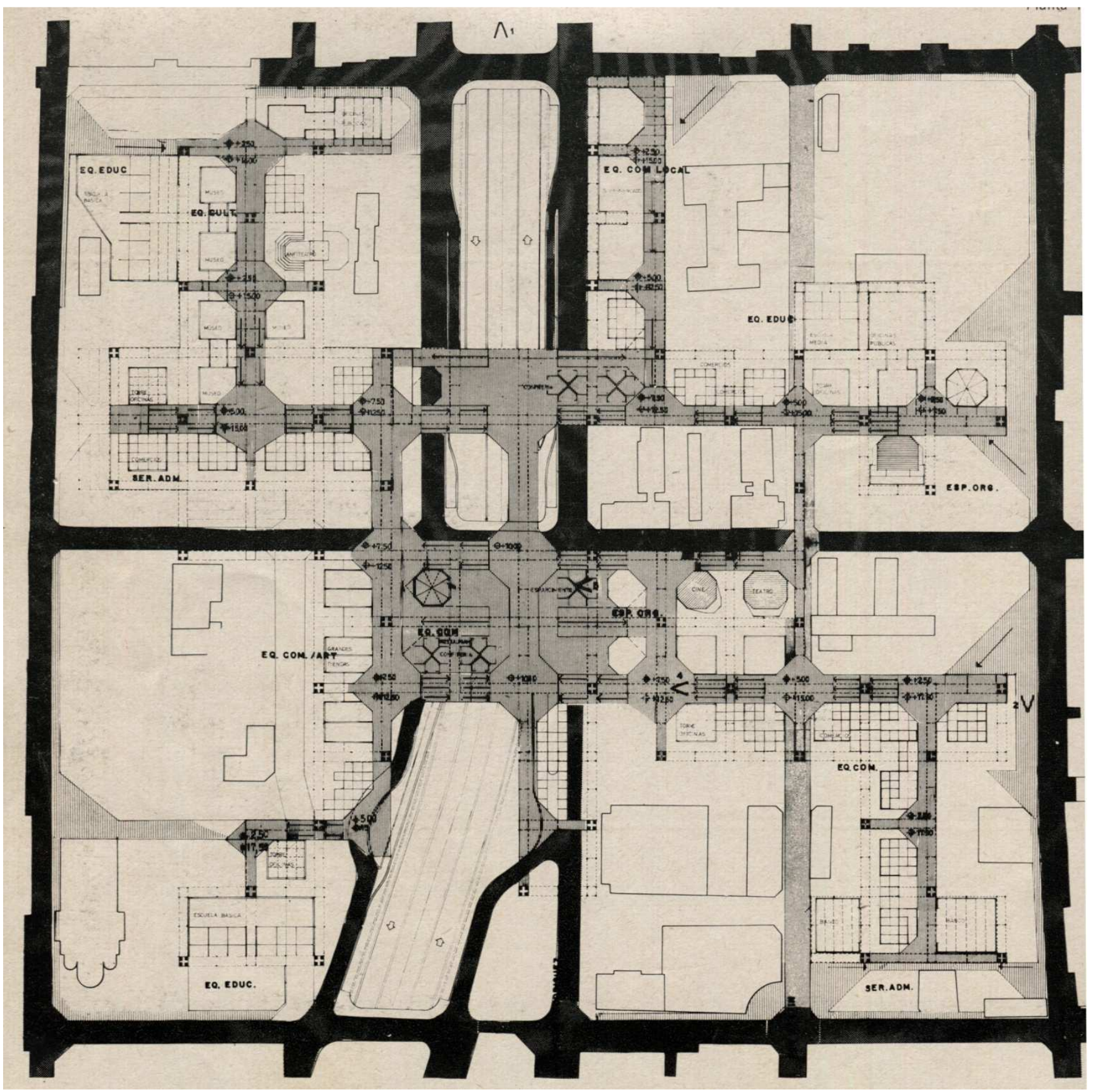

Figura 13: planta nivel $0.00 \mathrm{~m}$ identificando torres circulatorias y esquema macroestructural Fonte: Summa, n. 64/63, julio 1973, p. 130

La flexibilidad radical supera la escala edilicia para encarnarse en el nuevo sistema primario urbano propuesto, susceptible de soportar destinos indeterminados y desplazados en el tiempo, superponiendo y multiplicando en vertical y horizontal los 
flujos peatonales apoyados en recursos mecánicos alternativos al automóvil. Es clara la voluntad de sustituir el obsoleto damero de la ciudad barroca sudamericana, insuficiente para soportar las nuevas densidades, el tráfico y el recambio y ampliación continua de la infraestructura. Se postula suplantarlo por una trama abierta tridimensional, continua y multifuncional, capaz de absorber distintas situaciones y programas convivientes, que resolvería en si lo circulatorio, lo infraestructural y una importante concentración de servicios. Este "edificio ciudad" modular, concentrado en sólo un 20 \% del terreno, estaría sostenido y servido por torres de conexión vertical cada $30 \mathrm{~m}$ y conformado por la relación entre layers articulados verticalmente. El layer metropolitano sortearía con rampas los distintos niveles de estacionamiento, comercios y equipamientos a escala de ciudad, dispuestos en espacios modulares que rellenando los lugares entre o debajo de las viviendas conformarían un paseo urbano rico en visuales y situaciones arquitectónicas. El segundo layer se orienta a plazas altas, el comercio diario, las guarderías y el acceso desde arriba a las placas de vivienda, con actividades urbanas de características barriales.

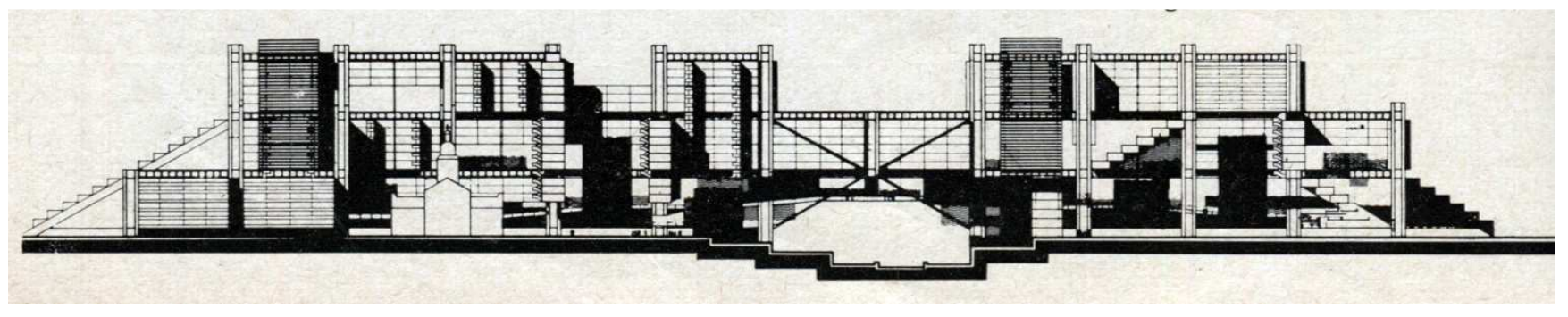

Figura 14: vista mostrando el atravesamiento de la avenida Norte-Sur

Fonte: Summa, n. 64/63, julio 1973, p. 130

Planteado su germen sobre el terreno objeto del concurso en Santiago Poniente, proponen expandir este esqueleto espacial de urbanidad siguiendo la impronta de las calles principales, salvando la cesura de la avenida Norte Sur y colonizando como pólipos vivificantes otros focos de centralidad al Norte y al Sur del centro histórico. Su expansión siempre se haría sobre una trama liberada del tráfico vehicular capturado en un ring de estacionamientos dentro de esqueletos megaestructurales que remiten a las torres planteadas por Kahn para el centro de Filadelfia.

En relación a esta suerte de damero tridimensional, y ocupando parcialmente los vacíos de la trama, se irían abrochando diferentes elementos programáticos en volúmenes discretos y fuertemente caracterizados: las mencionadas placas escalonadas de vivienda, las torres para oficinas y otros elementos potencialmente URBANA, V.6, no 8, jun.2014 - Dossiê: Cidade e Habitação na América Latina - CIEC/UNICAMP 
diversos y mutantes en función y configuración. Los autores hacen énfasis en esta síncopa volumétrica como una apertura a la variedad resultante de la mezcla de actividades y actores propia de lo urbano y dicen emular cierto desorden propio de la ciudad liberada a sus propias fuerzas, pero sin perder el sentido de unidad garantizado por la malla circulatoria tridimensional. La estrategia es una dialéctica expandida entre lo sirviente y lo servido, entre puntos fijos denominados sedentarios y elementos que se irían articulando gradualmente en el tiempo con una contundencia visual que alude a imágenes en suspensión contra el fondo dominante de la cordillera. Las referencias a su factibilidad son mínimas: un sistema constructivo prefabricado que, sin perder audacia, se justifica en la economía de escala y la repetición, y un costo inicial que sería equilibrado por la generación de tierra artificial en vertical.

\section{Indeterminación y virtualidad como sustento de la participación social}

El proyecto de Bares et al. supuso la optimización de la tecnología y el acervo tipológico disponibles para enriquecer la sociabilidad de la desterrada rue corridor a través de pasarelas peatonales elevadas sobre el suelo y el tráfico. Su confianza en la economía resultante de la repetición y la modulación constructiva justificaron la intensiva verticalización de las viviendas y de los espacios de asociación comunitaria y metropolitana. Las prefiguraciones de MSGSSV y STAFF se adentraron en el futuro para imaginar una ciudad en el espacio cuyos intercambios básicos transcurrieran a + 16,50 y $+33 \mathrm{~m}$ del suelo, aún en una ciudad frecuentemente afectada por los sismos. Sobre un suelo y un tejido urbano real que se desprecia, desplazan la invención tipológica del edificio a una megaestructura para forjar un nuevo estilo sudamericano de construir ciudad que colonizaría el damero obsoleto como un pólipo benéfico. Suplieron con fe las reflexiones sobre su construibilidad y factibilidad. Finalmente, el equipo rosarino conformado por Mario Corea, Adrián Caballero y Jackie Monzón revisó los postulados de la arquitectura móvil y las imágenes sugerentes del Paris Parallèle de Friedman, apoyándose en las lecciones del "cabshismo" (RIGOTTI, 2013) y en la propuesta atribuida a Woods (CHALJUB, 2010, p. 31) para Frankfurt, Römerberg. Más que soñar con un futuro libertario y lúdico, apretaban el puño y reclamaban la toma por asalto del suelo de la ciudad (ahora vertical, artificial y convenientemente servido) por parte de las clases subalternas.

En un discurso lleno de furia hacían un reclamo contra la tibieza de la primavera socialista chilena. El llamado a concurso, sus bases y presuposiciones urbanas, era tímidos e insuficientes. En nombre de una arquitectura fundada en una interpretación 
crítica del proceso social de construcción de la ciudad que abrevaba en el neomarxismo estructuralista de Lefebvre y Manuel Castells, proponían un diseño "de base ideológica modificada" (COREA; MONZON; CERVERA; CABALLERO, SHIRA, 1974, p.20) que prefería la pureza de las convicciones y la claridad enceguecedora de la verdad a la conveniencia de ganar un concurso. Claramente se inscribían en lo que Winograd (1973) denominó absolutos teóricos y hasta polémicos, por la escasa atención prestada a las exigencias del problema concreto y por impugnar los considerandos del concurso desde consideraciones políticas e ideológicas: no es casual que no recibiera ningún premio. De todos modos, el proyecto merece revisarse en tanto ofrece interesantes indicios de los aspectos más radicales de la polémica disciplinar que dominaba las aulas de arquitectura en el Cono Sur, en un delicado equilibrio entre el vanguardismo técnico moderno y los modelos de autoconstrucción (PREVI, 1969) que se estaban difundiendo en esos años, en particular en las páginas de Architectural Design, como soluciones para el Tercer Mundo.

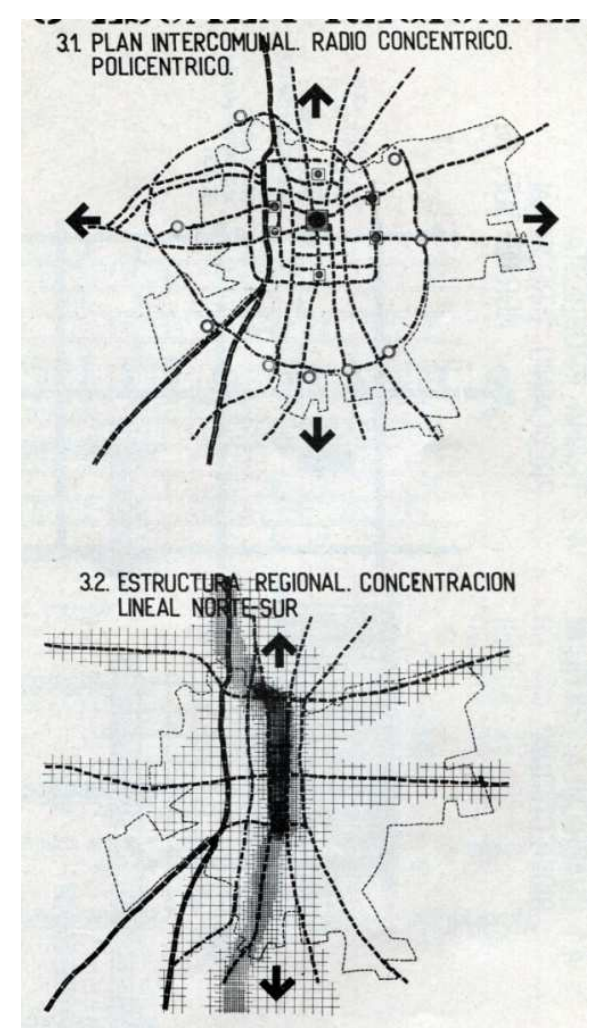

Figura 15: contraposición entre ciudad policéntrica y propuesta lineal

Fonte: CABALLERO; COREA; MONZON. Librería Técnica 1974, p. 98

El partido tomado se explica en relación a la trayectoria de Corea. Se había graduado en la Escuela de Arquitectura y Planeamiento de Rosario (1962), renovada en sus bases teóricas y pedagógicas por un grupo de arquitectos encabezado por el 
líder del Grupo Austral, Jorge Ferrari Hardoy. Tras una experiencia en el estudio de Sert, había realizado el master en Urban Design de Harvard colaborando con Fumihiko Maki en su propuesta para el sistema de movimientos de Boston (MAKI; COREA; LOZANO; MUNIZADA; WAMPLER, 1968). A su regreso, como profesor de la escuela de Rosario, fue intenso divulgador de las megaformas cuyos resultados en los ejercicios de alumnos destacó Banham (1976, p.157). Luego, tras su formación en estudios urbanos en la Architectural Association (1969/70), experimentó una reorientación teórica con una tesis sobre las contradicciones de la lucha de clases en la ciudad y conoció de cerca los coqueteos de la disciplina con la cibernética. Su regreso coincidió con la secuencia de los concursos para hospitales públicos en los que participó con su estudio a través de una propuesta preparatoria de su participación en el concurso para Santiago.

Se trató de una tesis "crítica" frente a las condiciones del hábitat en Chile que abjuraba de todo pragmatismo. Cercana a lo testimonial e infiltrada por la sociología y la teoría política, cuestionaba los tímidos intentos de reforma desde un camino pacífico hacia la sociedad sin clases. En su densa memoria descriptiva, tanto o más importante que la esquemática propuesta arquitectónica, el ataque al formalismo determinista y el estilismo de la "ideología funcionalista" eran sólo aspectos de una declamada resistencia a los mecanismos de dominación mediante el espacio organizado. En lugar de una composición más o menos abierta y reproducible en otros sectores de la ciudad, postularon una estructura posibilitante de su posterior utilización creativa por la práctica social organizada. Lo denominaban pasaje del "eje técnico estético" del funcionalismo, cuajado en edificios objeto que respondían a los requerimientos de las clases dominantes, a un "eje científico-social" conducente al diseño colectivo, donde el arquitecto se limitaba a formular elementos constantes y organizadores de un sistema indeterminado capaz de potencial el derecho de los usuarios a autodefinir su hábitat (CABALLERO; COREA; MONZON; 1974, p. 60). Se pretendía un cambio de las reglas de juego en la propiedad y uso de la tierra urbana, ahora multiplicada en vertical e irrigada de infraestructura y servicios urbanos.

El punto de partida era una impugnación a la estructura policéntrica del Plan Intercomunal de Santiago que estaría reeditando as presiones especulativas y a la renovación sectorizada implícita en el concurso no muy diferente al urban renewal del capitalismo desarrollado. Haciendo eje en la avenida Norte Sur, recuperaban el paradigma de la ciudad lineal soviética y proponían una extensión que, superando los 
límites de la ciudad existente, se expandiera atravesando el territorio, absorbiendo polos aislados de desarrollo y distribuyendo procesos de urbanización.

Sobre este cambio de reglas estructurales, el proyecto ensayaba un nuevo tejido tan homogéneo y potencialmente democrático como el damero, elusivo de toda centralidad y portador de una racionalidad implícita en el diseño que lo hacía apto para el despegue tecnológico de un país en desarrollo. Formal, espacial y estructuralmente se trataba de una composición secuencial generada por la superposición de barras con terminales abiertas que podían contraerse o expandirse sin afectar la idea fuerte de conjunto.

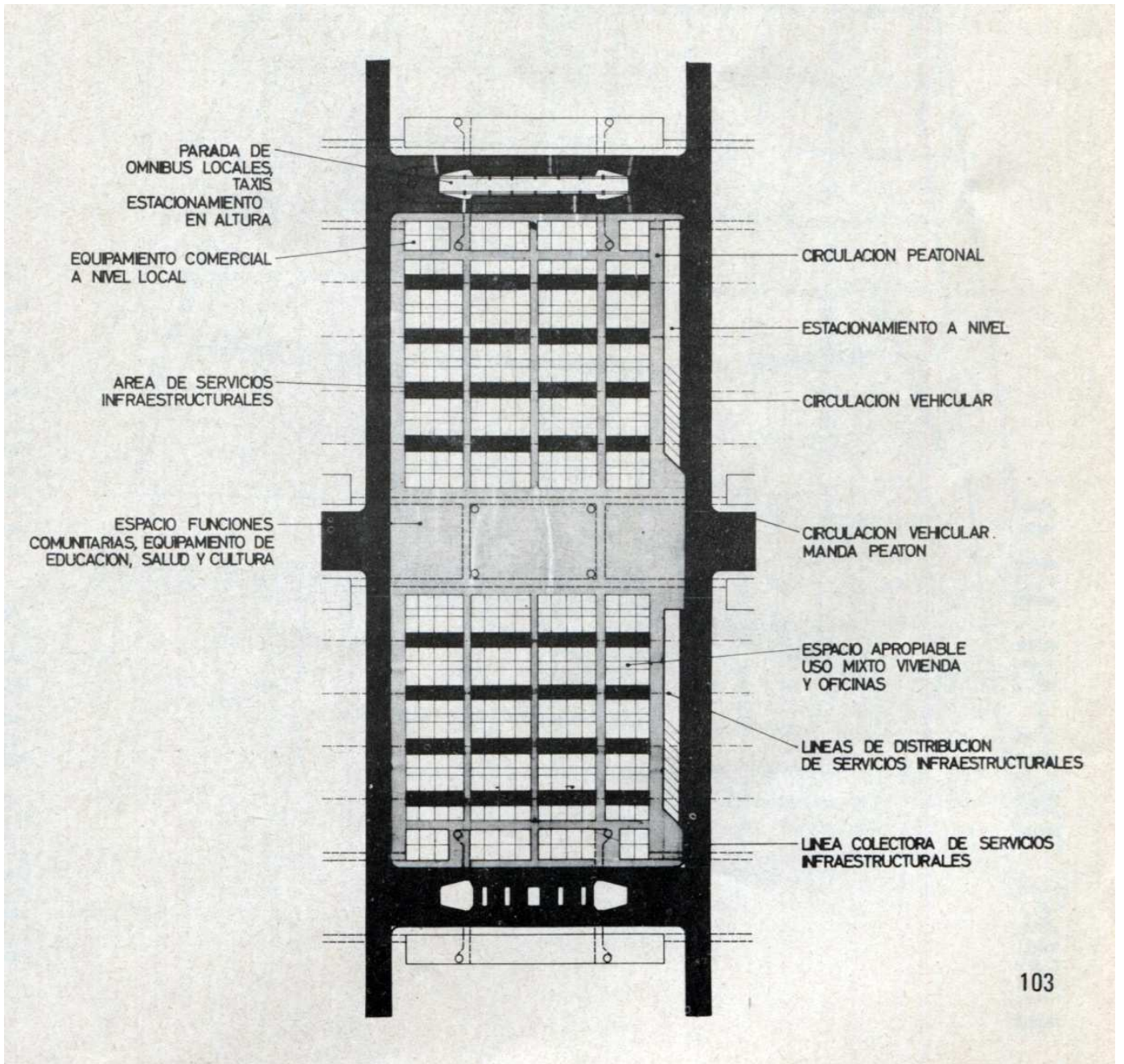

Figura 16: célula básica: estructura posibilitante

Fonte: CABALLERO; COREA; MONZON. Librería Técnica 1974, p. 103

Entender la propuesta sobre las viviendas ayuda a entender el resto. Fueron planteadas como un sistema neutro de superficies vacantes, sobre el suelo o sobre barras superpuestas de terreno artificial, definidas por la trama abierta y geométricamente normalizada de un sistema constructivo modular de $3 \times 6$ metros. 
De allí derivaba tanto la subdivisión de la tierra como la generación de espacios polifuncionales. La preocupación de la prefiguración de recintos se desplazaba al diseño de la trama circulatoria y de redes de servicio que llevan al paroxismo la identificación de la igualdad social con la homogeneidad geométrica de las formas. La otra preocupación era la ideación de un sistema constructivo modular prefabricado que además de permitir la definición y alteración de las unidades por los usuarios, impulsara la industrialización del país como componente necesario de un proyecto socialista. Sin renunciar a la acción demiúrgica del arquitecto y su saber técnico, se verifica aquí cierta convergencia con las soluciones propuestas en esos años por el MIR de toma de tierras en campamentos y/o soluciones progresivas de tierras con servicios mínimos.

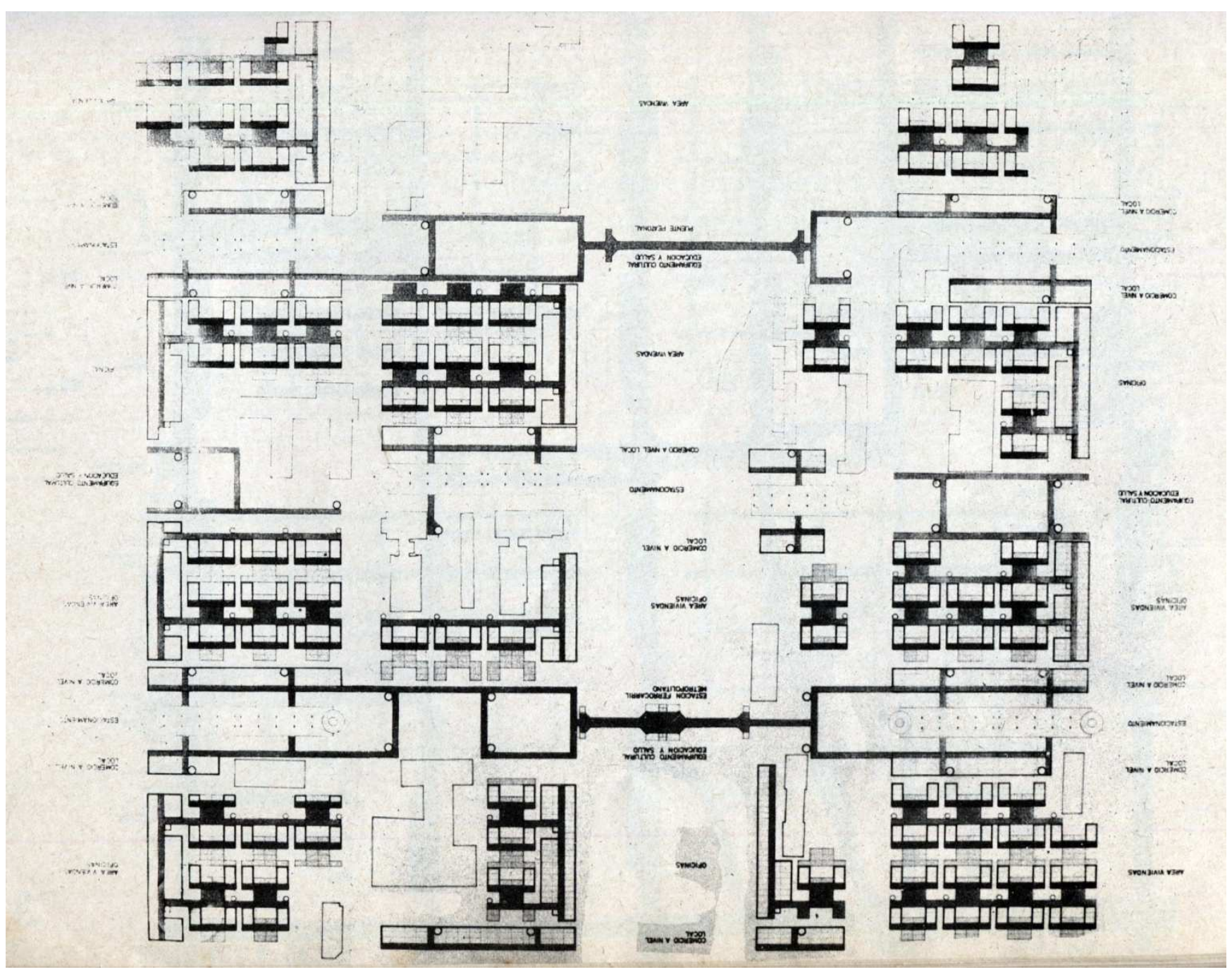

Figura 17: planta general particularizada a nivel de suelo

Fonte: CABALLERO; COREA; MONZON. Librería Técnica 1974, p. 98 
Estos gérmenes espaciales de vivienda se distribuían sobre un subdivisión teórica del suelo de $6 \times 13 \mathrm{~m}$ sobre la que se incorporaban barras transversales elevadas para espacios de intercambio y servicio a nivel metropolitano cada dos manzanas (sobre la circulación vehicular y las paradas de transporte público) y para funciones comunitarias y equipamientos de educación salud y cultura (sobre troncales de circulación peatonal). Planteados como corredores de urbanidad, formulaban un nuevo grano de ciudad compacta definida por el entramado de viviendas en torno a patios cuyo crecimiento también se basaría en la superposición de barras de terreno artificial en un juego similar a la estiba de tirantes de madera. Todo se disponía para la acción directa, no ya de individuos en pos de metas singulares de felicidad y confort como en el caso de Friedman, sino de pobladores organizados que no sólo harían oír su voz, sino que se apoderarían del espacio y operarían en su materialidad. No obstante, todavía dominaba una lógica funcionalista que asimilaba igualdad social con igualdad de distancias a las redes de servicio. Pocos ejemplos son más ilustrativos de la restricción del poder del espacio y la forma al centímetro, la recta y la indiferencia en la localización, un final catatónico para la declamada transfuncionalidad en una ciudad reconfigurada como tramas en movimiento (COREA, 1973).

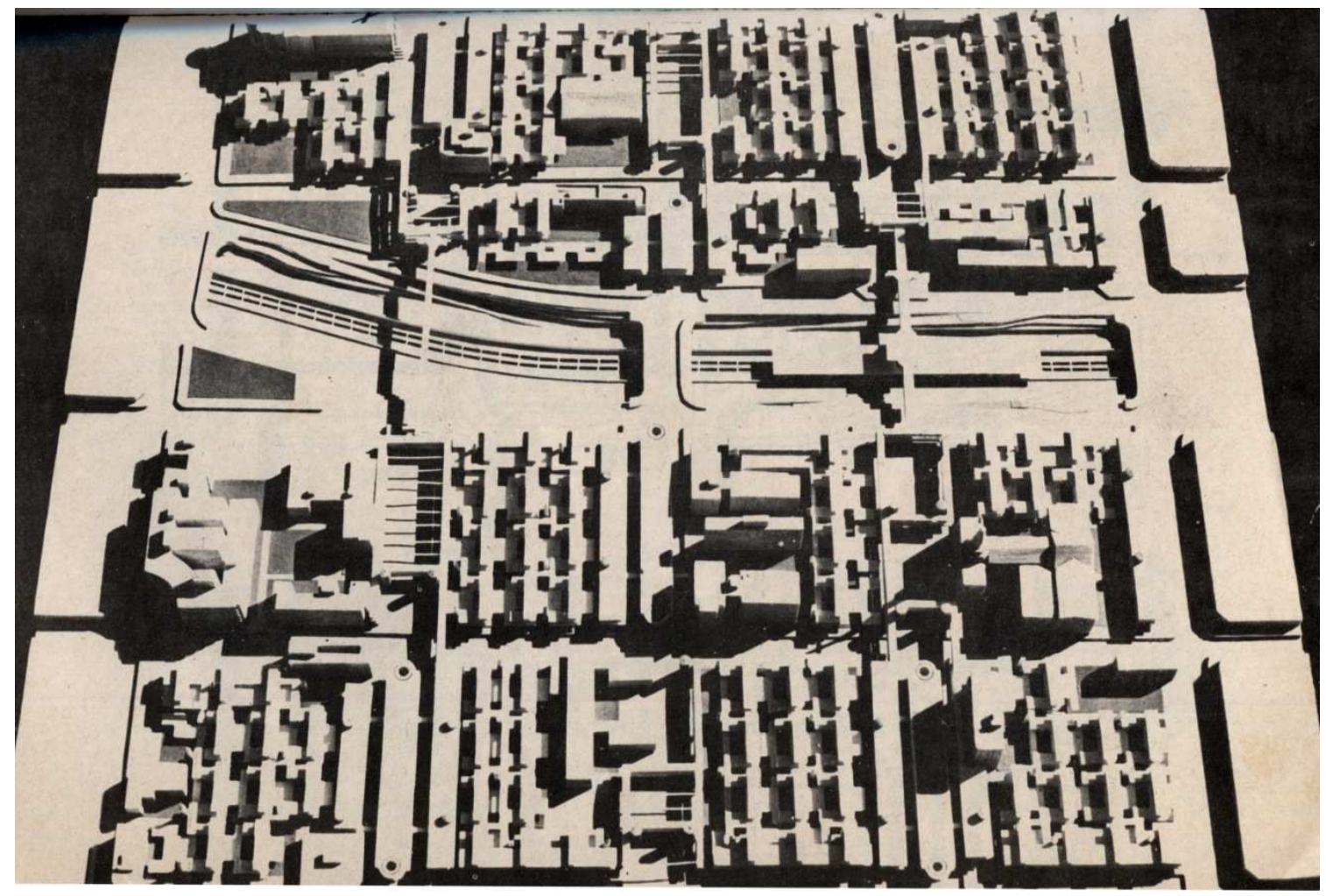

Figura 18: maqueta

Fonte: CABALLERO; COREA; MONZON. Librería Técnica 1974, p. 109

En síntesis, estamos frente a la buscada densidad a baja altura del groundscraper, lo que se ha denominado Thick 2-D (ALLEN, 2001), que prefirió 
permanecer en el registro seco y duro de la maqueta, asimilable a lo teórico y adecuado para encarnar la necesaria neutralidad de la indeterminación, a caer en la seducción blanda de las perspectivas convenientemente pobladas de gente, publicidades y vehículos en movimiento.

Se buscó la concentración y mezcla de usos a través de la densidad, aunque sin alcanzar los niveles planteado en las bases. Eludiendo la gran inversión inicial de la propuesta de MSGSSV y STAFF, se propuso una trama modular en tres niveles para dar verosimilitud a un nuevo tejido urbano compacto que sustituye la colección de edificios por un tejido tridimensional de calles, puentes, plazas y conexiones verticales. En la intersección entre lo abierto y lo cerrado se solaparon componentes lineales que miran hacia afuera y hacia adentro, entre lo público y lo privado. Fueron pensados con el sentido que Friedman (1958, p.17) otorgaba a las infraestructuras: elementos tridimensionales técnicos, neutros y rígidos, necesarios para la vida cotidiana, pero no directamente utilizados por sus habitantes, donde puede anidar un conjunto variado de entidades programáticas y espaciales.

Con cierto desparpajo, Corea et al. pretendieron abrir el camino a las posibilidades de la Arquitectura, superar el respeto temeroso a lo convencional y lo conocido y, al mismo tiempo, salvar el escollo de las grandes inversiones iniciales que condenaban a otros proyectos megaestructurales. Su objetivo último era invitar a nuevas formas de intervención, apropiación e identificación con la ciudad desde la participación directa, donde se reconocen derivas de los discursos cibernéticos sobre la indeterminación a los que Corea de había aproximado en su estancia en la Architectural Association (SILVESTRI, 2013). No es casual, entonces, la noción de virtualidad que los autores eligen para caracterizar su proyecto como "[...] reconocimiento de la dinámica potencial de materialización correspondiente a la práctica social posterior, contradictoriamente insertada en el modelo previo [...]" (CABALLERO; COREA; MONZON, 1974; pp. 76) y que resulta en la síntesis entre un modelo técnico arquitectónico y una participación creativa posterior de los usuarios que incluye el tiempo y la acción de múltiples actores en la definición de la forma y, consecuentemente, de sus connotaciones de orden e identidad.

\section{Un cierre}

Con este último gesto de casi autoimpugnación del hacer profesional, que comenzaba a propagarse como una cura a la borrachera reciente de cápsulas, 
macroestructuras y ciudades en el espacio, es posible terminar de reconstruir un estado de la Arquitectura en el Cono Sur previo al refugio temeroso en el saber del pobre, primero, y en los mandatos de la ciudad histórica, después. A su modo, marcando diferentes universos de referencia, las tres propuestas argentinas permiten trazar las coordenadas de un debate dominado por las apuestas y las fantasías implícitas tras esas arquitecturas gigantes desde las cuales se pretendió capturar, sintetizar, revitalizar, redefinir y hasta sustituir a la ciudad y sus potencialidades cívicas y sociales.

Se trata de proyectos que exploraron distintos recursos para capturar la pluralidad, la indeterminación, la cantidad y la complejidad apostando a la redefinición productiva de la textura urbana. Paradójicamente, al mismo tiempo se adentraban en las regulaciones propias de sistemas basados en la geometría, la modulación y la repetición, se abstenían de pensar en los matices de un espacio que se prefiere circunscribir a plataformas para la acción y frente al cual la hazaña era callar para permitir el acontecer. En todos los casos, se trataron de ensayos radicales nutridos en experiencias forjadas en la concepción de viviendas, cuyas estrategias se expanden a universos sociales y urbanos completos. Superposiciones verticales y almácigos estructurales nutridos de infraestructura y flujos circulatorios convergen en la artificialización total del suelo urbano. Se imaginan prefiguraciones cohesionadas por la contundencia del gesto único. En nombre de una nueva sociedad por venir se borran las huellas que la vida colectiva había dejado en el territorio.

Sus posibles excesos no deben ocultar la sensatez de los principios. La decidida apuesta de la Arquitectura para enfrentar los problemas de la cantidad y la complejidad, la indeterminación y la transformabilidad ha sido recuperada en las últimas décadas, junto a miradas celebratorias sobre estos desafíos que rozaron la megalomanía, siempre con la coartada de abrirse a las pulsiones de prospectivos usuarios diluidos en el absoluto de la masa.

\section{REFERENCIAS}

ALIATA, Fernando; LOYOLA, Omar (2011). La Transformación de la ciudad en el camino al socialismo. El concurso para la remodelación del centro de Santiago de Chile (1972). Actas de las Primeras Jornadas Arqueología de la contemporaneidad. Cultura del espacio y cultura política en la ciudad latinoamericana (1966-2001). La Plata: HiTePAC FAU UNL. 
ALLEN, Stan (2001). Urbanism: the Thick 2-D. In: SARKIS, Hashim. Le Corbusier's Venice Hospital and the Mat Building Revival. Munich, Nueva York: Prestel, p. 118-126.

ÁREA DE REMODELACIÓN en el centro de Santiago (1973). AUCA, Santiago de Chile, n. 24-25, setiembre, p. 23-34.

ARQUITECTURA - CIUDAD. Chile 1972 (1975). SUMMA, Buenos Aires, n. 87, marzo, p. 23-50.

BANHAM, Reyner (1976). Megastructure. Urban Futures of the Recent Past. Londres: Thames and Hudson.

BARES, Enrique; BO, Santiago; GARCÍA, Tomás; GERMANI, Roberto; SESSA, Emilio (1975). Área de remodelación en el centro de Santiago de Chile. SUMMA, Buenos Aires, n. 87, marzo, p. 23-51.

CABALlERO, Adrián; COREA, Mario; MONZÓN, Yackie (1974). Propuesta de remodelación para el área central de Santiago de Chile. Contribución a un enfoque crítico del diseño. Buenos Aires: Librería Técnica CP67.

CHALJUB, Bénédicte (2010). Candilis, Josic \& Woods. Paris: Éditions du Patrimoine. COREA, Mario (1973). El diseño transfuncional. La estructura posibilitante, Córdoba, FAU UNC.

COREA, Mario; MONZÓN, Yackie; CERVERA, Amalia; CABALLERO, Adrián; SHIIRA, Roberto (1974). Contribución a un enfoque crítico del diseño. Buenos Aires: Librería Técnica CP67.

ESTUDIO STAFF (1973). Remodelación del Centro de Santiago, Chile. SUMMA, Buenos Aires, n. 64-65, junio, p.128-132.

FRIEDMAN, Yona (1958). L'architecture mobile. Paris, Tournai.

GIEDION, Sigfried (1955). Precedentes históricos del Corazón. In: ROGERS, E. N.; SERT, J. L.; TYRWHITT, J. El Corazón de la Ciudad: por una vida más humana de la comunidad. Barcelona: Hoelpi S. L., p. 17-25.

HABRAKEN, N. John et al. (1972) Supports, an Alternative to Mass Housing. Londres: The Architectural Press.

LAWNER, Miguel (1991). La Remodelación del Centro de Santiago. Santiago de Chile: Taller de Vivienda Social.

MAKI, Fumihiko (1964). Investigations in Colective Form. St. Louis: The School of Architecture, Univ. of Washington.

MAKI, Fumihiko; COREA, Mario; LOZANO, Eduardo; MUNIZAGA, Gustavo; WAMPLER, Ian (1968). Sistemas de movimiento en la ciudad. A\&P, Rosario, n. 8, p. 5-23. 
RIGOTTI, Ana María (2012a). Fósiles de futuro: megaestructuras. Block, Buenos Aires UTDT, n. 9, julio, p. 18-31.

RIGOTTI, Ana María (2012b). Megaestructuras: aire libre y urbanidad en probeta. Encuentro Internacional Arquitectura, clima y culturas modernas, Buenos Aires.

RIGOTTI, Ana María (2013). Un lugar en la cartografía de las megaformas. In: La "teoría de sistemas" en la transformación de la cultura urbana. Arquitectura, ciudad y territorio entre el profesionalismo y la tecno-utopía (1950-1980). Buenos Aires: UTDT, p. 168-181.

SESSA, Emilio (2011). Arquitectura de vivienda social y construcción de la ciudad: una mirada actual del Concurso Internacional: Área de remodelación en el centro de Santiago de Chile. Revista de Urbanismo, Santiago de Chile, n. 24, junio, p. 10-19. SERT, J. L. (1955). Debate sobre las plazas italianas. In: ROGERS, E. N.; SERT, J. L.; TYRWHITT, J. El Corazón de la Ciudad: por una vida más humana de la comunidad. Barcelona: Hoelpi S. L., p. 74-80.

SILVESTRI, Graciela. Alma de arquitecto: conformación histórica del "habitus" de los proyectistas del hábitat (Argentina, 1962-1976). Segundas jornadas Arqueología de la contemporaneidad. Cultura política y cultura del espacio en la ciudad latinoamericana (1950-2000). La Plata: HiTePAC FAU UNL.

SMITHSON, Alison (1974). How to recognize and read Mat Building. Mainstream architecture as it has developed towards the mat building. Architectural Design, Londres, n. 9, septiembre, p. 313-333.

WAISMAN, Marina (1973). Hacer es la consigna. SUMMA, Buenos Aires, n. 64-65, junio, p. 24-33.

WINOGRAD, Marcos (1972). Imprecisiones sobre el concurso de Santiago de Chile. SUMMA, Buenos Aires, n. 55, noviembre, p. 18-19. 